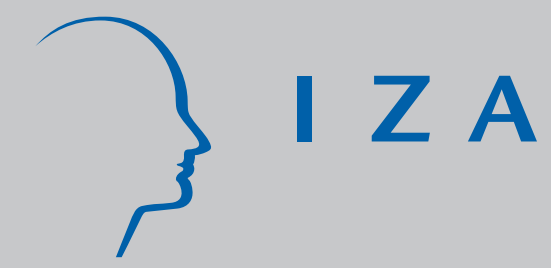

IZA DP No. 340

How Does Imperfect Competition in the Labor Market Affect Unemployment Policies?

Xavier Wauthy

Yves Zenou

August 2001 


\title{
How Does Imperfect Competition in the Labor Market Affect Unemployment Policies?
}

\author{
Xavier Wauthy \\ Facultés Universitaires Saint-Louis and CORE, \\ Université Catholique de Louvain \\ Yves Zenou \\ University of Southampton, CEPR and IZA, Bonn
}

Discussion Paper No. 340

August 2001

\author{
IZA \\ P.O. Box 7240 \\ D-53072 Bonn \\ Germany \\ Tel.: +49-228-3894-0 \\ Fax: +49-228-3894-210 \\ Email: iza@iza.org
}

This Discussion Paper is issued within the framework of IZA's research area The Welfare State and Labor Markets. Any opinions expressed here are those of the author(s) and not those of the institute. Research disseminated by IZA may include views on policy, but the institute itself takes no institutional policy positions.

The Institute for the Study of Labor (IZA) in Bonn is a local and virtual international research center and a place of communication between science, politics and business. IZA is an independent, nonprofit limited liability company (Gesellschaft mit beschränkter Haftung) supported by the Deutsche Post AG. The center is associated with the University of Bonn and offers a stimulating research environment through its research networks, research support, and visitors and doctoral programs. IZA engages in (i) original and internationally competitive research in all fields of labor economics, (ii) development of policy concepts, and (iii) dissemination of research results and concepts to the interested public. The current research program deals with (1) mobility and flexibility of labor markets, (2) internationalization of labor markets and European integration, (3) the welfare state and labor markets, (4) labor markets in transition, (5) the future of work, (6) project evaluation and (7) general labor economics.

IZA Discussion Papers often represent preliminary work and are circulated to encourage discussion. Citation of such a paper should account for its provisional character. 
IZA Discussion Paper No. 340

August 2001

\section{ABSTRACT \\ How Does Imperfect Competition in the Labor Market Affect Unemployment Policies?*}

We consider a continuum of workers ranked according to their abilities to acquire education and two firms with different technologies that imperfectly compete in wages to attract these workers. Once employed, each worker bears an education cost proportional to his/her initial ability, this cost being higher in the high-technology firm. At the Nash equilibrium, we show that the unemployed workers are those with the lowest initial abilities. We then study different policies that subsidy either the education cost or wages and compare them. We found that the first best allocation can only be implemented by selective policies. We then analyze second best non-selective policies that do not discriminate between workers and firms and show that, in terms of welfare, subsidizing education costs or wages is strictly equivalent.

JEL Classification: H20, J31, L13

Keywords: Nash equilibrium in wages, heterogeneous workers and firms, inequality, unemployment policies

Yves Zenou

Department of Economics

University of Southamptom

Southampton SO17 1BJ

U.K.

Tel.: + (44) 2380593264

Fax: + (44) 2380593858

Email: yz@soton.ac.uk

"The authors would like to thank Marcus Berliant, Jean Gabszewicz and Pierre Pestieau for many helpful comments. We are also grateful to two anonymous referees and the Editor, John Conley, for valuable suggestions. 


\section{Introduction}

In the last two decades, it has been observed that low-skilled workers earn relative lower wages and face relative higher rates of unemployment compared to higher-skilled workers. For example, in the U.S., between 1963 and 1989, wages for the least skilled have fallen by about $5 \%$ whereas for the most skilled they have increased by about 40\% (Katz, Loveman and Blanchflower, 1992, Juhn, Murphy and Pierce, 1993). In European countries, where relative wage flexibility is lower, this inequality between skilled and unskilled workers has been reflected through different access to employment. Even though there has not been a decrease in relative wages, the unemployment rate of the less-skilled workers has sharply increased (OECD, 1996).

In this paper, we propose a simple theoretical framework that captures some of these ideas by focussing on the interaction between firms using different technologies and workers' heterogeneity. In our model, there are in fact two technologies (or two firms) in the economy: an old one and a new one. Workers are all heterogeneous in their ability of acquiring education. We assume that, in order to get a job, a worker must be perfectly matched with the firm and thus must incur an education cost proportional to his/her initial ability. Since the new technology requires a higher level of skill than the old one, the same worker bears a higher education cost to work in the high-tech firm. In this framework, the most able individuals tend to work in the high-tech firm and the less-skilled ones in the other firm. Moreover, because workers unevenly trade off between the two firms, each firm faces a finitely elastic labor supply and thus enjoys some monopsonistic power over its workforce. At the labor market equilibrium, inequalities in terms of net wages and access to employment arise because of labor heterogeneity and imperfect competition. Indeed, we show, at the Nash equilibrium, that the unemployed workers are those with the lowest initial abilities. On one hand, unemployment can be considered as voluntary since gross wages offer insufficient remuneration after education costs are substracted. On the other, unemployment can also be considered as involuntary due to the non-cooperative wage setting process. In the absence of strategic interactions generated by this process, full employment may prevail.

We then study different policies that either subsidy the education cost or wages (see in particular Layard, 1994, 1995). We model our problem in two stages. In the first stage, the government proposes one of its policies anticipating the market outcome of the second stage in which firms set wages noncooperatively. We found that the first best allocation can only be implemented by selective policies. We then analyze second best non-selective policies that 
do not discriminate between workers and firms (because for example of legal constraints) and show that subsidizing education costs or wages is equivalent in terms of welfare.

Our model is related to other studies that introduce labor heterogeneity and imperfect competition in the labor market. In Stevens (1994), firms have an incentive to differentiate their skill requirements in order to obtain monopsony power in the labor market. Hamilton, Thisse and Zenou (2000) and Wauthy and Zenou (2000) assume that firms and workers are heterogeneous, which implies that firms have oligopsonistic power in the labor market and thus charge a lower wage than the competitive one. Chang and Wang (1996) consider a setting in which a firm derives market power over its incumbent workers from the fact that rival firms do not know how much specific training these workers have acquired. Finally, Sattinger (1993) develops different models in which a large number of workers and a small number of jobs (or firms) have to be assigned to each other, even though firms have no market power. Our paper is quite different since the focus is on inequality, unemployment and policies whereas in the above models in which full employment prevails the focus is mainly on the financing of the education cost and on job matching. ${ }^{1}$

The rest of the paper is organized as follows. We state the basic model in section 2 and compute the Nash equilibrium in section 3. We then analyze the first-best allocation and the two selective policies in section 4. Section 5 is devoted to the second-best (non-selective) policies. Finally, section 6 concludes.

\section{The model}

The economy consists of two sectors: a high-technology and a low-technology one. In each sector, there is one representative firm. This set-up is admittedly highly stylized since each firm is in fact a monopsonist within its sector. Formally, it requires that either only one firm exists in each sector or several firms collude to act as one monopsonist. ${ }^{2}$ This last possibility is not so unreasonable since workers decide where to work by comparing net wages across sectors and, in each sector, firms require the same level of qualification. This implies that workers may enjoy very limited mobility within the sector so that some market

\footnotetext{
${ }^{1}$ More recently, some papers have studied unemployment in the context of heterogenous workers and firms but with horizontal differentiation. See in particular Bhaskar and To, 1999, Marimon and Zilibotti, 1999, Fiorillo et al., 2000, Thisse and Zenou (2000) and Jellal, Thisse and Zenou (2001). Our present paper is quite different from these approaches in particular because (i) workers and firms are vertically differentiated, (ii) we study education and wage second-best policies.

${ }^{2}$ Observe that our framework could easily introduce many identical firms in each sector. It suffices to consider a Cournot game instead of a Bertrand one. All our main results would remain the same.
} 
power prevails in each sector, even if firms are numerous. ${ }^{3}$

In order to focus on the interaction between these two sectors and the pool of heterogeneous workers, we have chosen the following assumptions. Each firm, 1 and 2, is characterized by a scalar $E_{i}(i=1,2)$, that indicates the skill level required by each of them, and a real constant marginal productivity, $H$, and $L$ respectively, with $E_{1}>E_{2}>0$ and $H>L>0$. Hence firm 1 can be thought of as the 'skilled' or high-technology firm and firm 2 as the 'unskilled' or low-technology firm.

In the labor market, firms imperfectly compete in wages to attract workers, whereas in the product market they are price takers. Each firm maximizes its profit by setting their wages non-cooperatively. The profit functions are respectively given by:

$$
\begin{aligned}
& \Pi_{1}\left(w_{1}, w_{2}\right)=\left(H-w_{1}\right) S_{1}\left(w_{1}, w_{2}\right) \\
& \Pi_{2}\left(w_{1}, w_{2}\right)=\left(L-w_{2}\right) S_{2}\left(w_{1}, w_{2}\right)
\end{aligned}
$$

where $S_{i}\left(w_{1}, w_{2}\right)$ is the labor supply addressed to firm $i$.

There is a continuum of workers ranked by their increasing ability of learning education and distributed uniformly in the interval $\left[0, t^{+}\right]$. For simplicity, we assume that the density of workers in each point of the interval is taken to be unity so that the total number of workers in the economy is equal to $t^{+}$. Each individual is characterized by a parameter $t \in\left[0, t^{+}\right]$. This parameter is defined in a way that the education cost is increasing in $t$. In order to work in firm $i$, a worker of type $t$ must bear an education cost equal to $t E_{i}(i=1,2)$. In other words, even though there a continuum of ex ante heterogenous workers, ex post these workers can only achieve two levels of education: high-school graduate (with marginal productivity L) or university graduate (with marginal productivity $H$ ).

We assume that workers bear the totality of the education cost. This assumption is quite natural since education is basically general human capital and thus firms are not likely to finance it because it would be too easily transferred from one firm to another within a sector. We also assume that each worker is endowed with an indivisible unit of labor and receives the same unemployment benefit, whatever his/her unemployment duration. For simplicity, we assume that this benefit is normalized to zero.

Thus, in order to decide whether to work or not, a worker trades off $w_{i}$ and $t E_{i}$, where $t E_{i}$ is the reservation wage for a worker of type $t$, i.e. the wage

\footnotetext{
${ }^{3} \mathrm{~A}$ way to justify this intuition is the possibility of different industries where there is specific human capital. If on top of that, firms also locate in different cities, the number of potential employers for any given worker may become really low. Firms may then act as local monopsonies. The only limit to their market power is the possibility for workers to change industry or city, which is costly. Thus, monopsony power is bounded by mobility costs in a broad sense. Our analysis of monopsonistic firms could be considered as valid when these mobility costs are sufficiently large.
} 
level that makes him/her indifferent between accepting to work in firm $i$ and be unemployed. According to our previous assumptions, the reservation wage is positively related to workers' ability. When $w_{i} \geq t E_{i}(i=1,2)$, the worker decides whether to work in firm 1 or 2 . The trade off is now between the wage differential $w_{1}-w_{2}$ and the education cost differential $t\left(E_{1}-E_{2}\right)$. For instance, if $w_{1}-w_{2}>t\left(E_{1}-E_{2}\right)$, the worker of type $t$ decides to work in firm 1 (the skilled one). The education cost schedule, or equivalently the reservation wage distribution, defined as a function of the type of workers, is depicted in Figure 1.

The following comments can be drawn from this figure. First, working in firm 1 requires a higher education cost than in firm 2, for all workers, i.e. $t E_{1}>t E_{2}$ for all $t \in\left[0, t^{+}\right]$. This captures the idea of a skilled and an unskilled firm. Second, the education cost differential increases with $t$, indicating that the lower the ability, the larger the education cost differential, and thus the more difficult is the access to firm 1 . In order to make the worker of type $\tilde{t}$ indifferent between the two firms, there must be a wage differential of $\Delta$. Obviously, for this wage differential, workers of type $t<\tilde{t}$ (resp. $t>\tilde{t}$ ) work in firm 1 (resp. firm 2).

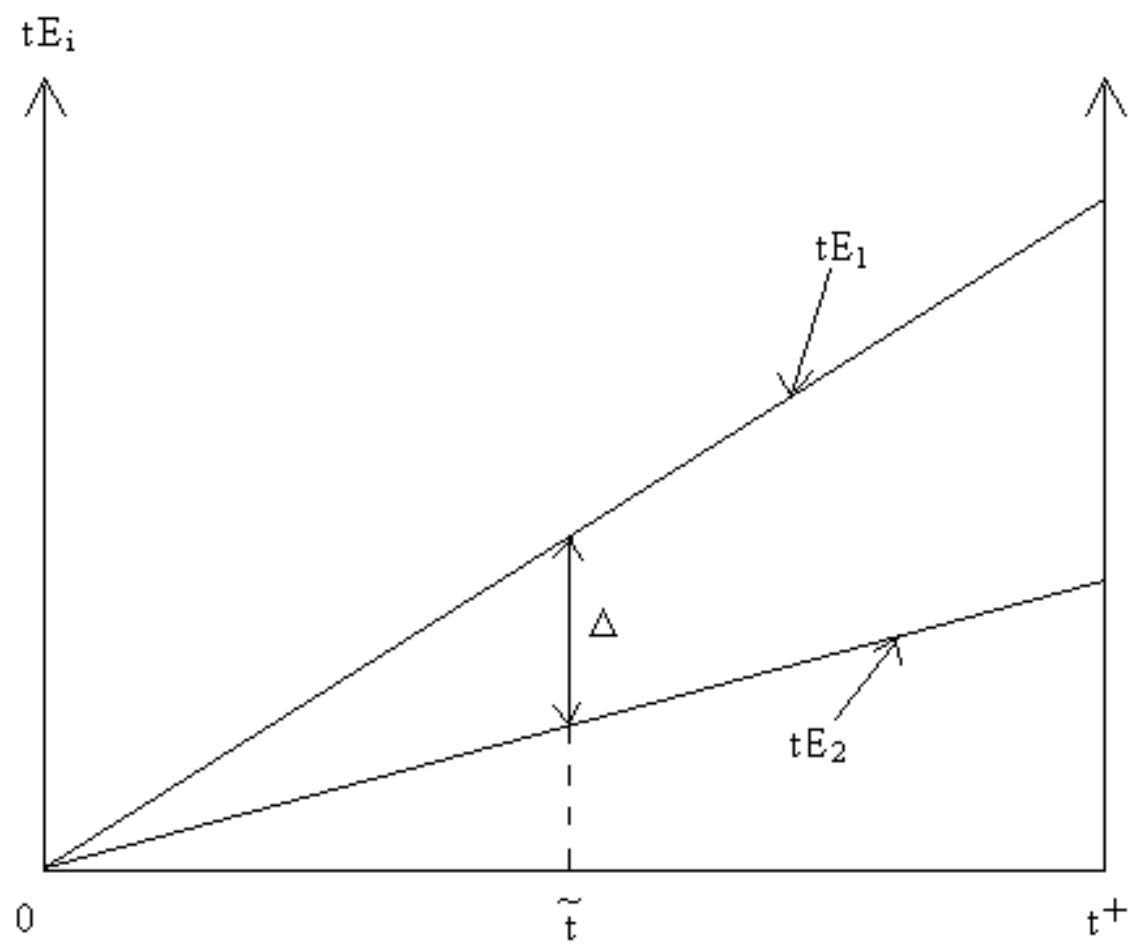

Figure 1: Reservation Wage Distributions 


\section{Labor market equilibrium and the structure of unemployment}

\subsection{Labor supplies}

The worker $i$ 's net wage, $w_{i}^{n}$, directly depends on his/her ability. It is given by:

$$
w_{i}^{n}=w_{i}-t E_{i}
$$

A worker is thus willing to accept a job if it yields the highest positive net wage; he/she prefers to stay unemployed if the net wage is negative. In the present model, staying unemployed essentially means that given prevailing wages, learning a technology is too costly for the lowest-skilled workers. In Figure 2, we have depicted the distribution of net wages for initial wage levels of $\bar{w}_{1}$ and $\bar{w}_{2}$. Observe that firm 1's net wage function is steeper than firm 2's. This reflects the difference in skill levels and thus in education cost. Observe also that workers of type $t \geq \overline{t_{2}}$ are enjoying negative net wages in firms 1 and 2 and therefore will stay unemployed. On the other hand, since workers of type $t \in\left[\bar{t}_{1}, \bar{t}_{2}\right]$ obtain a positive net wage in firm 2 and a negative one in firm 1 , they decide to work in firm 2 . This is also true for workers of type $t \in\left[\tilde{t}, \bar{t}_{1}\right]$ who enjoy the highest net wage in firm 2. Moreover, workers of type $t<\tilde{t}$ choose to work in firm 1 for the same reason.

We may therefore summarize the allocation of workers for wage levels $\bar{w}_{1}$ and $\bar{w}_{2}$ as follows:

$$
\left\{\begin{array}{llr}
S_{1}\left(\bar{w}_{1}, \bar{w}_{2}\right) & = & \tilde{t} \\
S_{2}\left(\bar{w}_{1}, \bar{w}_{2}\right) & = & \bar{t}_{2}-\tilde{t} \\
U\left(\bar{w}_{1}, \bar{w}_{2}\right) & = & t^{+}-\bar{t}_{2}
\end{array}\right.
$$

where $U\left(\bar{w}_{1}, \bar{w}_{2}\right)$ defines the level of the unemployment given the wage policy. Furthermore, the marginal worker of type $\tilde{t}$ (indifferent between working in firm 1 or 2$)$, is defined such that $w_{2}-\tilde{t} E_{2}=w_{1}-\tilde{t} E_{1}$, i.e.

$$
\tilde{t}\left(w_{1}, w_{2}\right)=\frac{w_{1}-w_{2}}{E_{1}-E_{2}}
$$

whereas the worker of type $\bar{t}_{i}$ (indifferent between working in firm $i$ and staying unemployed) is equal to:

$$
\bar{t}_{i}=\frac{w_{i}}{E_{i}} \quad i=1,2
$$

The wage competition process is then easily understood by using Figure 2. Assuming that $\tilde{w}_{1}$ is given, a rise in the wage offered by firm 2 yields an upward parallel shift of $w_{2}^{n}(t)$ and marginal workers of types $\widetilde{t}$ and $\bar{t}_{2}$ move respectively to the left and to the right. Therefore, the labor supply addressed 
to firm 2 increases. This is due to two reasons: first, some workers now prefer firm 2 to firm 1, and second, some individuals now find it more profitable to work in firm 2 instead of staying unemployed. This is not the case when one considers an increase of $\bar{w}_{1}$ while keeping $\bar{w}_{2}$ unchanged. Indeed, in this case, firm 1's labor supply increases because, and that is the only reason, workers who wanted previously to work in firm 2 now decide to work in firm 1 (the marginal worker of type $\tilde{t}$ now moves to the right whereas the one of type $\overline{t_{2}}$ is not affected and thus does not change his/her position). ${ }^{4}$ Observe finally that full employment requires that the worker of type $t^{+}$enjoys a positive net wage in at least one firm, typically firm 2.

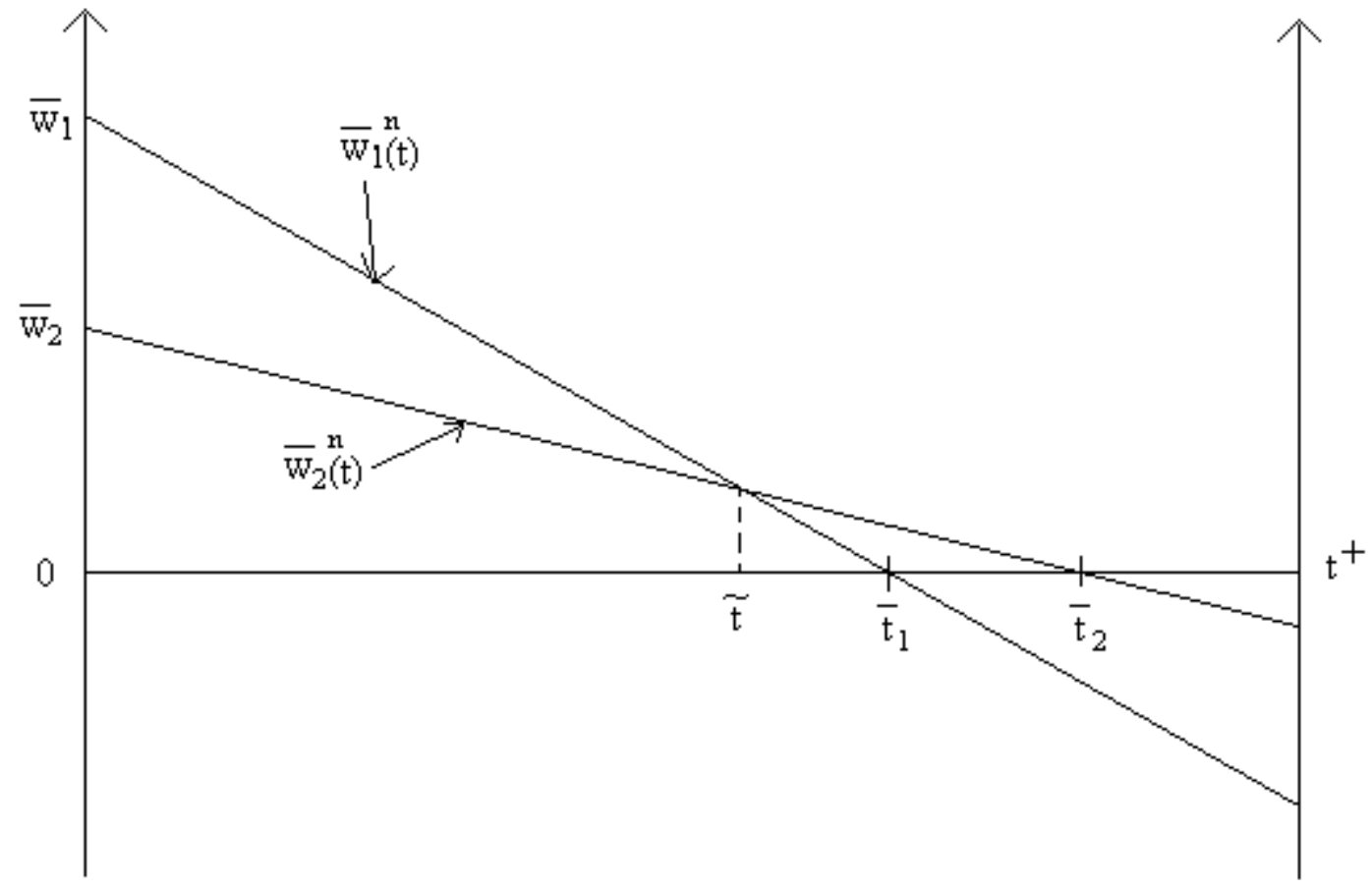

Figure 2: Net Wage Distributions

By generalizing the argument above and by using equations (3) and (4) we can characterize labor supplies in the following way.

$$
S_{1}\left(w_{1}, \bar{w}_{2}\right)= \begin{cases}0 & \text { when } w_{1}<\bar{w}_{2} \\ \frac{w_{1}-\bar{w}_{2}}{\left(E_{1}-E_{2}\right)} & \text { when } \bar{w}_{2} \leq w_{1}<\frac{\bar{w}_{2}}{E_{2}} E_{1} \\ \frac{w_{1}}{E_{1}} & \text { when } \frac{\bar{w}_{2}}{E_{2}} E_{1}<w_{1}<t^{+} E_{1} \\ t^{+} & \text {when } w_{1} \geq \bar{w}_{2}+t^{+}\left(E_{1}-E_{2}\right)\end{cases}
$$

\footnotetext{
${ }^{4}$ In order to attract workers who preferred otherwise to stay unemployed, it is necessary for firm 1 that these workers enjoy a negative net wage in firm 2 . Therefore, we need that $\bar{t}_{1}>\bar{t}_{2}$, which implies that firm 2's labor supply is equal to 0 .
} 
$S_{2}\left(\bar{w}_{1}, w_{2}\right)= \begin{cases}0 & \text { when } w_{2}<\frac{\bar{w}_{1}}{E_{1}} E_{2} \\ \frac{w_{2}}{E_{2}}-\frac{\bar{w}_{1}-w_{2}}{\left(E_{1}-E_{2}\right)} & \text { when } \frac{\bar{w}_{1}}{E_{1}} E_{2} \leq w_{2} \leq t^{+} E_{2} \\ t^{+}-\frac{\bar{w}_{1}-w_{2}}{\left(E_{1}-E_{2}\right)} & \text { when } t^{+} E_{2} \leq w_{2}<\bar{w}_{1} \\ t^{+} & \text {when } w_{2} \geq \bar{w}_{1}\end{cases}$

\subsection{Equilibrium wages}

In equilibrium, two market configurations may be obtained: either wages are such that all workers are willing to work, either some of them are left unemployed because they are offered negative net wages in both firms. In the latter case, only low ability workers stay unemployed. Since we are interested in unemployment policies, we will focus only on this configuration.

In order to show the unique Nash equilibrium in wages, when unemployment prevails and the two firms are active, we proceed in three steps. First $(i)$, we characterize our equilibrium by identifying the necessary restrictions on parameters. Second $(i i)$, given these restrictions, we derive the unique equilibrium wage candidate. Finally $(i i i)$, we show that the restrictions on parameters identified in $(i)$ are satisfied at the Nash equilibrium.

Starting with $(i)$, we must consider the second part of $S_{1}\left(w_{1}, \bar{w}_{2}\right)$ and $S_{2}\left(\bar{w}_{1}, w_{2}\right)$ defined by equations (5b) and (6b) since they ensure that both some workers do not take a job and the two firms are active. By assuming that $\overline{t_{1}}<\overline{t_{2}}$, which is equivalent to $w_{1} / E_{1}<w_{2} / E_{2}$, we rule out cases (5c)-(6a) and (5a)-(6d) in which only one firm is active (preemption). By also assuming that $w_{2}<t^{+} E_{2}$, we are guaranteed that there will be unemployment in equilibrium.

Our second step $(\mathrm{ii})$ is to calculate the equilibrium Nash candidate. For that, we first compute the reaction functions by maximizing (1) and (2) with respect to wages. We obtain:

$$
\begin{gathered}
w_{1}=\frac{H+w_{2}}{2}=\phi_{1}\left(w_{2}\right) \\
w_{2}=\frac{L}{2}+w_{1} \frac{E_{2}}{2 E_{1}}=\phi_{2}\left(w_{1}\right)
\end{gathered}
$$

By combining these two reaction functions, we easily obtain the following equilibrium candidate for a market configuration with unemployment and no preemption:

$$
\begin{gathered}
w_{1}^{N}=(2 H+L) \frac{E_{1}}{4 E_{1}-E_{2}} \\
w_{2}^{N}=\left(2 L E_{1}+H E_{2}\right) \frac{1}{4 E_{1}-E_{2}}
\end{gathered}
$$


Our last step ( iii) is to verify that our two conditions $w_{1} / E_{1}<w_{2} / E_{2}$ (no preemption) and $w_{2}<t^{+} E_{2}$ (unemployment) are satisfied at the equilibrium candidate. Let us first check that $w_{2}^{N}<t^{+} E_{2}$, i.e. the worker with the highest reservation wage prefers to stay unemployed instead of working in firm 2 . This is equivalent to:

$$
t^{+}>\frac{H E_{2}+2 L E_{1}}{\left(4 E_{1}-E_{2}\right) E_{2}}
$$

When condition (9a) holds, some workers remain unemployed in equilibrium: they are precisely those who are characterized by the lowest ability. In our model, the level of unemployment is thus measured by $t^{+}-t_{u}{ }^{5}$ For the rest of the paper, we assume that $t^{+}$is large enough to ensure that full employment is never reached. The second requirement for no preemption is such that $w_{1}^{N} / E_{1}<w_{2}^{N} / E_{2}$. A sufficient condition is:

$$
\frac{H}{E_{1}}<\frac{L}{E_{2}}
$$

This condition on the parameters implies that the two firms are active in a competitive labor market. The following proposition summarizes our results:

Proposition 1 Under (9a) and (9b), the labor market equilibrium is characterized by a unique Nash equilibrium in wages given by (7) and (8) and by a level of unemployment equal to $t^{+}-t_{u}$.

The following comments are in order. First, even though ex ante there is a continuum of heterogeneous workers, ex post the economy is characterized by three types of workers: the high-skill ones that works in the high-technology firm, the low-skill individuals that are employed in the low-technology firm and the unemployed that are the workers with the lowest initial skills. However, in terms of utility, since workers bear all the education costs, there is ex post a continuum of utilities for the employed workers and a unique utility level (the unemployment benefit) for the unemployed. It is thus because workers are heterogeneous and because different technologies are available in the economy that unemployment and inequality prevail in equilibrium. In this respect, our model captures some of the stylized facts described in the introduction.

Second, the equilibrium wage differential depends negatively on $L$ and positively on $H$ whereas $t_{u}$ is a positive function of $H$ and $L$. In other words, an increase in workers' productivity reduces the wage differential as well as the level of unemployment since the competition in the labor market becomes fiercer, reflecting the externalities associated with the non-cooperative wagesetting framework: sector 1's specific shock spills over to the other sector. We

\footnotetext{
${ }^{5}$ For notation purpose, we use $t_{u}$ instead of $\bar{t}_{2}$. It is of course the marginal worker who is indifferent between working in firm 2 and staying unemployed.
} 
have thus a model in which workers' and firms' heterogeneity as well as imperfect competition lead to inequality both in terms of wages and unemployment.

Third, this proposition shows, at the Nash equilibrium, that the unemployed workers are those with the lowest initial abilities. On one hand, the unemployment can be viewed as voluntary since gross wages offer insufficient remuneration after education costs are substracted. On the other, the unemployment can also be viewed as involuntary due to the non-cooperative wage setting process, since, in the absence of the strategic interactions generated by this process, full employment may prevail. Indeed, it is easy to check that unemployment may prevail even if marginal productivities are sufficiently high $\left(H>t^{+} E_{1}\right.$ and $\left.L>t^{+} E_{2}\right)$. In other words, should firm behave competitively and set wages at the level of marginal productivity, unemployment would disappear. The other main reason is that firms are not allowed to discriminate in wages. This implies that, in order to attract one more worker, it is necessary to increase wages for everybody. It is important to recall that unemployment implies that some types of workers are not employed. The problem here is independent of the absolute density of the interval $\left[0, t^{+}\right]$: should workers be more or less numerous, our conclusion would stay the same.

Finally, the implications of a minimum wage legislation are easy to trace. The minimum wage must be set above $w_{2}^{N}$ in order to be effective. When this condition is satisfied, the low technology sector pays the minimum wage, so that unemployment decreases. Wages increase also in the high-technology sector but the wage differential decreases, so that the size of this last sector shrinks. This is in accordance with the empirical studies of Card and Krueger (1995) who stipulate that a minimum wage legislation must be imposed in sectors where firms have monopsonistic power.

Within this context, an obvious policy for lowering unemployment consists in reducing qualification costs. By making education less costly, the government rends it more profitable for each workers to train, and thus to become employable in the labor market by meeting the low qualification standards (non-selective policies). Such policies are indeed observed in the form of qualification programs launched or financed by governments. The government can also reduce the labor cost by subsidizing labor at the firm level, and more particularly labor in firm 2 since low ability workers tend to work in this firm (selective policies).

\section{First-best allocation and selective policies}

\subsection{The first-best allocation}

Let us consider a utilitarian social welfare function defined by the sum of firms' profits and workers' utility. It is equal to: 


$$
\begin{aligned}
W & =\int_{0}^{\tilde{t}}\left(H-w_{1}\right) d t+\int_{\tilde{t}}^{t_{u}}\left(L-w_{2}\right) d t+\int_{0}^{\tilde{t}}\left(w_{1}-t E_{1}\right) d t+\int_{\tilde{t}}^{t_{u}}\left(w_{2}-t E_{2}\right) d t \\
& =\int_{0}^{\tilde{t}}\left(H-t E_{1}\right) d t+\int_{\tilde{t}}^{t_{u}}\left(L-t E_{2}\right) d t
\end{aligned}
$$

The second line of (10) shows that the total welfare is divided between the welfare of the skilled and the unskilled firm respectively. Observe that wages do not enter directly in the total welfare, but only indirectly through $t_{u}$ and $\tilde{t}$. This is due to the fact that the role of wages is solely to determine how the surplus is shared between firms and workers.

The first best allocation is defined for the values of $t_{u}$ and $\tilde{t}$ that maximize the total welfare (10). By derivating (10) with respect to $t_{u}$ and $\tilde{t}$, we obtain the following first best values:

$$
\begin{gathered}
\tilde{t}^{e}=\frac{H-L}{E_{1}-E_{2}} \\
t_{u}^{e}=\frac{L}{E_{2}}
\end{gathered}
$$

Not surprisingly, (11) and (12) correspond to the competitive allocations, i.e., the ones that yield wages to equate their marginal productivities $\left(w_{1}^{e}=H\right.$ and $\left.w_{2}^{e}=L\right)$. Recall that we have assumed condition (9b) in order to rule out preemption. Moreover, by using the Nash equilibrium in wages defined in (7) and (8) and by plugging them into (3) and (4), we obtain the following Nash allocations:

$$
\begin{gathered}
\widetilde{t}^{N}=\frac{H\left(2 E_{1}-E_{2}\right)-L E_{1}}{\left(4 E_{1}-E_{2}\right)\left(E_{1}-E_{2}\right)} \\
t_{u}^{N}=\frac{H E_{2}+2 L E_{1}}{\left(4 E_{1}-E_{2}\right) E_{2}}
\end{gathered}
$$

We obtain here a standard result of second best allocation since the wage competition between firms is imperfect. The reason of this inefficiency is easily identified: in general, the allocation of workers is not efficient since $\tilde{t}^{N}$ is different from $\tilde{t}^{e}$ and the level of employment is too low. Formally,

$$
\begin{gathered}
\widetilde{t}^{N} \gtrless \widetilde{t}^{e} \quad \text { iff } \quad \frac{3 E_{1}-E_{2}}{2 E_{1}} \gtrless \frac{H}{L} \\
t_{u}^{N}<t_{u}^{e}
\end{gathered}
$$

Thus we can identify two possible effects from the government policy. The first one illustrated by (15) is the reallocation effect ( $R E$ hereafter) whereas 
the second one (16) is the employment effect ( $E E$ hereafter). By affecting equilibrium net wages, the government can reallocate the workers between the two firms and cut the level of unemployment. The relevant question here is: can the government reach the first best allocation defined by (11) and (12) or is it restricted to second best policies? Let us first consider the selective policies in which the government can discriminate between workers or firms.

\subsection{Selective policies}

We start with the policy which consists of subsiding differently wages in the two firms. Denote by $s_{i}(i=1,2)$ the ad valorem wage subsidy for firm $i$. The profit functions (1) and (2) rewrite:

$$
\begin{aligned}
& \Pi_{1}\left(w_{1}, w_{2}, s_{1}\right)=\left(H-w_{1}\left(1-s_{1}\right)\right) S_{1}\left(w_{1}, w_{2}\right) \\
& \Pi_{2}\left(w_{1}, w_{2}, s_{2}\right)=\left(L-w_{2}\left(1-s_{2}\right)\right) S_{2}\left(w_{1}, w_{2}\right)
\end{aligned}
$$

It is easy to show that the Nash equilibrium in wages are respectively:

$$
\begin{gathered}
w_{1}^{s, N}=\frac{\left[2 H\left(1-s_{2}\right)+L\left(1-s_{1}\right)\right] E_{1}}{\left(4 E_{1}-E_{2}\right)\left(1-s_{1}\right)\left(1-s_{2}\right)} \\
w_{2}^{s, N}=\frac{H E_{2}\left(1-s_{2}\right)+2 L\left(1-s_{1}\right) E_{1}}{\left(4 E_{1}-E_{2}\right)\left(1-s_{1}\right)\left(1-s_{2}\right)}
\end{gathered}
$$

By plugging (19) and (20) into (3) and (4), and by equating these new equations with (11) and (12), we easily obtain:

$$
\begin{gathered}
s_{1}^{*}=\frac{H-L}{2 H-L}<1 \\
s_{2}^{*}=\frac{L E_{1}-H E_{2}}{2 L E_{1}-H E_{2}}<1
\end{gathered}
$$

with

$$
\lim _{E_{2} \rightarrow E_{1}} s_{2}^{*}=s_{1}^{*}
$$

Then, by using condition (9b), we have:

$$
0<s_{2}^{*}<s_{1}^{*}<1
$$

Proposition 2 The government can reach the first best allocation by subsiding firms 1 and 2 according to the selective wage subsidies defined by (21) and (22).

The following comments are in order. First, in implementing a selective policy, the government must set a larger subsidy in firm 1 than in firm 2 . This is due to the fact that the policy aims not only at reducing the level of unemployment but also at reallocating the workers between the two firms. Since our 
setting implies that the high-technology sector generates a greater surplus, it puts a high bias towards reallocating workers in this sector. If the only objective of the government was the reduction of unemployment, then the subsidy of one sector would have been enough. However, since misallocation effects are present, the government must combine the two instruments, $s_{1}$ and $s_{2}$, in order to restore the first best allocation. Even if both subsidies affect directly the equilibrium wages (19) and (20), and thus $t_{u}$ and $\widetilde{t}$, the optimal policy to restore the first best allocation is to set $s_{1}^{*}>s_{2}^{*}$ in order to put more weight on the firm that generates most of the inefficiency, i.e. on firm 1 since it enjoys more market power. ${ }^{6}$ The same result has been obtained in another context (dual labor market with efficiency wage) by Bulow and Summers (1986). Their result is even more extreme since they advocate the fact that the government should only subsidy wages in the primary sector. Second, when $E_{2}$ gets closer to $E_{1}$, i.e., the education cost differential between the two firms is lower, the difference between $s_{1}^{*}$ and $s_{2}^{*}$ becomes lower since the $R E$ is smaller. Third, when $H$ increases or when $L$ decreases, the difference between $s_{1}^{*}$ and $s_{2}^{*}$ becomes greater because the larger the productivity differential, the higher the welfare cost due to the misallocation of workers between firms. Last, in general, it is advocated that the government should subsidy only workers choosing firm 2 (low-skill workers) since it is the "critical workforce" with respect to the unemployment problem (see for example Drèze and Malinvaud (1994) who propose to subsidy only the low-qualified workers). In our setting, such a policy will clearly be efficient in lowering unemployment. Indeed, it basically allows low-technology firms to offer more attractive wages to workers, given the prevailing productivity conditions. In this respect, our results point out the fact that cutting unemployment alone leads to a misallocation of workers thus to a social cost. The problem them amounts to compare the relative importance of this social costs against the benefits of increasing employment.

The second selective policy consists in subsiding the education cost. Profit functions are the same as (1) and (2) and, by denoting by $g_{i}(i=1,2)$, the $a d$ valorem education cost subsidy, we obtain the Nash equilibrium in wages:

$$
\begin{gathered}
w_{1}^{g, N}=\frac{(2 H+L)\left(1-g_{1}\right) E_{1}}{4 E_{1}\left(1-g_{1}\right)-E_{2}\left(1-g_{2}\right)} \\
w_{2}^{g, N}=\frac{H E_{2}\left(1-g_{2}\right)+2 L E_{1}\left(1-g_{1}\right)}{4 E_{1}\left(1-g_{1}\right)-E_{2}\left(1-g_{2}\right)}
\end{gathered}
$$

As before we obtain the following the optimal subsidies:

$$
g_{1}^{*}=\frac{E_{1} E_{2} H^{3}+H^{2} L\left(5 E_{1}^{2}-6 E_{1} E_{2}+E_{2}^{2}\right)+H L^{2}\left(4 E_{1}^{2}+E_{1} E_{2}\right)+2 E_{1} E_{2} L^{3}}{E_{1}(H-L)\left(E_{2} H^{2}+H L\left(4 E_{1}-3 E_{2}\right)-2 E_{2} L^{2}\right)}
$$

\footnotetext{
${ }^{6}$ Observe that if firms could wage discriminate, they would also achieve the first-best allocation.
} 


$$
g_{2}^{*}=\frac{H^{2}\left(2 E_{2}-E_{1}\right)+H L\left(2 E_{1}-E_{2}\right)-2 E_{2} L^{2}}{\left(E_{2} H^{2}+H L\left(4 E_{1}-3 E_{2}\right)-2 E_{2} L^{2}\right)}
$$

These expressions are very cumbersome but this is not surprising since education cost subsidies affect net wages in two opposite ways. They rise equilibrium gross wages but at the same time they reduce the level of education cost. In the previous case, wages subsidies were affecting only gross wages, and thus affected firms' strategies directly. More importantly, $g_{1}^{*}$ and $g_{2}^{*}$ are not defined for all the parameter constellations. In general, $g_{1}^{*}$ must be greater than $g_{2}^{*}$ and there is no guarantee that $g_{1}^{*}<1$. This shows that a selective policy based on the education cost subsidy is more problematic to implement than the one based on wage subsidy. Indeed, the first best allocation is not always possible in the former case whereas it is always true in the latter one.

\section{Non-selective policies}

In a lot of countries, the government cannot implement a selective policy because of legal or institutional constraints. For example, unions or political parties may be opposed to discriminatory policies especially ours which induces the government to subsidy more the wage of the skilled firm in order to reach the first best allocation. In this case, the government will like to achieve a second best outcome by maximizing the total welfare. To this end, it proposes two different non-selective policies, an education policy and a labor cost policy. However, it must take into account the non-cooperative behavior of firms, i.e., the welfare function must incorporate the firms' wage setting through $\widetilde{t}^{N}$ and $t_{u}^{N}$.

\subsection{The education policy}

We now assume that the government subsidizes a fraction $\gamma$ of the total education cost whatever the ability of the worker is and whatever the firm chosen by the worker. Observe however that the lower the ability, the larger the subsidy, which in turn favors low-ability workers. We consider now the effect of this policy on the competition between firms.

Formally, the reservation wage of an individual of type $t$ working in firm $i$ is defined by

$$
t(1-\gamma) E_{i}
$$

As a direct consequence of the government policy, reservation wage distributions are driven downwards. This changes the value of $t_{u}$ and $\tilde{t}$ since it affects the net wage differential. Formally we have:

$$
t_{u}^{\gamma}=\frac{w_{2}}{(1-\gamma) E_{2}}>t_{u}
$$




$$
\tilde{t^{\gamma}}=\frac{w_{1}-w_{2}}{(1-\gamma)\left(E_{1}-E_{2}\right)}>\tilde{t}
$$

These two equations imply that $S_{i}^{\gamma}\left(w_{1}, w_{2}\right)=\frac{1}{1-\gamma} S_{i}\left(w_{1}, w_{2}\right)$. Therefore first order conditions are not modified and the level of wages in equilibrium is not affected by the introduction of the education policy. Hence, subsidizing workers' education cost does not influence firms' strategies. Marginal profits are not modified and equilibrium wages are still given by equations (7) and (8). However, equilibrium labor supplies change since reservation wages decrease. We have:

$$
\begin{aligned}
\widetilde{t}^{\gamma, N} & =\frac{1}{1-\gamma} \widetilde{t}^{N} \\
t_{u}^{\gamma, N} & =\frac{1}{1-\gamma} t_{u}^{N}
\end{aligned}
$$

The education policy has an unambiguous effect on unemployment. Wages are not modified whereas reservation wages decrease and thus unemployment is lower. Moreover, this policy also implies a reallocation of the workforce. Since $\tilde{t}^{\gamma, N}$ is greater than $\tilde{t}^{N}$, there will be more people working in the highqualification firm. In short, the education policy implies that workers whose ability is ranging from $\widetilde{t}^{N}$ to $\widetilde{t}^{\gamma, N}$ switch from firm 2 to firm 1 whereas workers whose ability is between $t_{u}^{N}$ and $t_{u}^{\gamma, N}$ now work in firm 2 instead of being unemployed.

\subsection{The labor cost policy}

The labor cost policy consists in providing each firm with an ad valorem subsidy $\sigma$ for every worker it hires. This subsidy $\sigma$ is proportional to the wage offered by the firm. In this case, reservation wages are still defined by $t E_{i}$, $(i=1,2)$, but equilibrium wages are different because firms' marginal profits change. Contrarily to the previous policy, firms' strategies are affected by this policy. Profit functions are now defined by:

$$
\begin{aligned}
& \Pi_{1}\left(w_{1}, w_{2}, \sigma\right)=\left[H-(1-\sigma) w_{1}\right] S_{1}\left(w_{1}, w_{2}\right) \\
& \Pi_{2}\left(w_{1}, w_{2}, \sigma\right)=\left[L-(1-\sigma) w_{2}\right] S_{2}\left(w_{1}, w_{2}\right)
\end{aligned}
$$

This yields the equilibrium wage candidates to be:

$$
\begin{gathered}
w_{1}^{\sigma, N}=\frac{(2 H+L)}{1-\sigma} \frac{E_{1}}{4 E_{1}-E_{2}} \\
w_{2}^{\sigma, N}=\frac{\left(2 L E_{1}+H E_{2}\right)}{1-\sigma} \frac{1}{4 E_{1}-E_{2}}
\end{gathered}
$$


Observe that $w_{i}^{\sigma, N}=\frac{w_{i}^{N}}{1-\sigma}$, and therefore the following equilibrium relations are easily established:

$$
\begin{aligned}
t_{u}^{\sigma, N} & =\frac{t_{u}^{N}}{1-\sigma} \\
\tilde{t}^{\sigma, N} & =\frac{\widetilde{t}^{N}}{1-\sigma}
\end{aligned}
$$

Note that these relations differ from those established for the education policy since the former are valid only in equilibrium whereas the latter hold for all values of $w_{1}$ and $w_{2}$.

\subsection{Analysis of the two policies}

We first consider the welfare effects of the two policies. By comparing the allocations of the education policy in (31) and (32) and the ones of the labor cost policy in (37) and (38), it is obvious that, in equilibrium, the two policies lead to the same level of welfare for $\sigma=\gamma$. Thus, the welfare analysis is equivalent for the two policies. The following proposition summarizes our discussion. ${ }^{7}$

Proposition 3 Consider only the non-selective policies. In the education policy, the equilibrium wages are not affected whereas the reservation wages are. In the labor cost policy, the reservation wages are not modified whereas the equilibrium wages are. However, the equilibrium net wages in both policies are identical. This leads to the same level of optimal subsidy.

It is immediate to see that the first best allocation can never be reached by a non-selective policy since the government has one instrument $(\sigma$ or $\gamma)$ and two targets (11) and (12). Formally, it is equivalent to solve a system of two equations with one unknown. Thus we now turn to second best policies by first focussing on the education policy. All the results of the education policy can be interpreted the same way for the labor cost policy. The welfare function (10) rewrites:

$$
W(\gamma)=\int_{0}^{\tilde{t}^{\gamma, N}}\left(H-t E_{1}\right) d t+\int_{\tilde{t}^{\gamma, N}}^{t_{u}^{\gamma, N}}\left(L-t E_{2}\right) d t
$$

First, observe that this welfare is a net one since it takes implicitly into account both the gain for the workers, i.e., $\int_{0}^{\tilde{t}^{\gamma, N}} \gamma t E_{1} d t+\int_{\tilde{t}^{\gamma, N}}^{t_{u}^{\gamma, N}} \gamma t E_{2} d t$ and the cost

\footnotetext{
${ }^{7}$ Observe that the equivalence between subsidizing education and subsidizing wages is not a standard result in labour economics. It is due in fact to the specificity of our model. Indeed, the problem is one of ex ante under-investment by workers. The incentive schedule offered by firms is not first best because of monopsony. But having a benevolent planner giving a subsidy ex ante on training or ex post on wages is just the same.
} 
for the government, i.e., $-\int_{0}^{\tilde{t}^{\gamma, N}} \gamma t E_{1} d t-\int_{\tilde{t}^{\gamma}, N}^{t_{u}^{\gamma, N}} \gamma t E_{2} d t$. Obviously, these two terms cancel when added and the welfare is thus equal to (39). One possible interpretation is that the policy is financed by a lump-sum tax on firms. What is left in (39) is just the allocation effects. This leads us to our second observation. The education policy has two effects: a reallocation effect $(R E)$ that induces workers to change firms because of their new reservation wages and an employment effect $(E E)$ that induces some workers to accept now a job in firm 2. Formally, we have:

$$
\frac{\partial W}{\partial \gamma}=\frac{\partial W}{\partial \widetilde{t^{\gamma}, N}} \frac{\partial \widetilde{t}^{\gamma, N}}{\partial \gamma}+\frac{\partial W}{\partial t_{u}^{\gamma, N}} \frac{\partial t_{u}^{\gamma, N}}{\partial \gamma}
$$

Observe that according to (31) and (32), $\frac{\partial \tilde{t}^{\gamma, N}}{\partial \gamma}$ and $\frac{\partial t_{u}^{\gamma, N}}{\partial \gamma}$ are positive. Moreover, the first term of the RHS of (40), the $R E$, is positive as long as $\widetilde{t}^{\gamma, N}=\frac{1}{1-\gamma} \widetilde{t}^{N}<\frac{H-L}{E_{1}-E_{2}}=\widetilde{t}^{e}$. Increasing $\gamma$ always implies that more individuals are willing to work in firm 1 . However, we know from (15) that independently of the policy, there could be already too many workers in firm 1 at the Nash equilibrium compared to the first best allocation. In other words, increasing $\gamma$ can be inefficient. Thus, if $\widetilde{t}^{N}<\widetilde{t^{e}}$, the education policy has a positive effect up to $\widetilde{t}^{N}=\widetilde{t}^{e}$ whereas if $\widetilde{t}^{N}>\widetilde{t}^{e}$, this policy has always a negative reallocation effect. The second term of the RHS of (40) describes the EE. By (16), it is always efficient to increase $\gamma$ up to $t_{u}^{N}=t_{u}^{e}$. When these two effects are combined, the net result depends on the parameters $H, L, E_{1}$ and $E_{2}$. It is useful to evaluate these two effects, the $R E$ and the $E E$, when $\gamma=0$, i.e., when there is no government policy. It is easy to check that the $E E$ is always strictly positive whereas the $R E$ depends on:

$$
R E_{\mid \gamma=0} \quad \geq_{0} \quad \text { if } \quad \widetilde{t}^{N}<\widetilde{t}^{e} \Leftrightarrow \frac{H}{L}>\frac{3 E_{1}-E_{2}}{2 E_{1}}
$$

After simplifications of (40), the FOC yields:

$$
\left[(H-L)-\frac{\widetilde{t}}{1-\gamma}\left(E_{1}-E_{2}\right)\right] \widetilde{t}^{N}+\left[L-\frac{t_{u}^{N}}{1-\gamma} E_{2}\right] t_{u}^{N}=0
$$

Solving this expression for $\gamma$ leads to:

$$
\gamma^{*}=1-\frac{\left(\widetilde{t^{N}}\right)^{2}\left(E_{1}-E_{2}\right)+\left(t_{u}^{N}\right)^{2} E_{2}}{\widetilde{t}^{N}(H-L)+t_{u}^{N} L}
$$

where $\widetilde{t}^{N}$ and $t_{u}^{N}$ are respectively defined by (13) and (14).

In order to decide which level of $\gamma^{*}$ leads to a second best, the government must balance between the two effects, the $R E$ and the $E E$, by comparing the different parameters $H, L, E_{1}$ and $E_{2}$. However, $\gamma^{*}$ defined by (43) can be less or equal to 0 (in which case $\gamma^{*}=0$ ), or positive but strictly less than 1 (it 
is readily verified from (43) that $\gamma^{*}$ cannot be equal to 1 ). Let us study first the solution $\gamma^{*}=0$. Since we know that the level of employment at the Nash equilibrium is always less than the one at the first best solution, i.e., the $E E$ is positive when $\gamma=0$, and since by (41), the $R E$ can either be positive or negative when $\gamma=0$, the solution is $\gamma^{*}=0$ when the (negative) $R E$ dominates the (positive) $E E$. Formally, the solution is defined for the constellation of the parameters $H, L, E_{1}$ and $E_{2}$ such that $\gamma^{*} \leq 0$ in (43). Second, for which values of the parameters, the government sets a very large $\gamma^{*}$ ? Intuitively, either when both the $R E$ and the $E E$ are still positive for this large value of $\gamma^{*}$ or when one effect dominates the other one for this large value of $\gamma^{*}$. One consequence of this result is that the level of employment (resp. the level of allocation between the two types of workers) can be greater than the first best one if the $R E$ (resp. $E E$ ) is sufficiently large. Last, in all other cases, the solution is when $\gamma^{*}$ is defined by (43) with $\left.\gamma^{*} \in\right] 0,1[$. Observe that this analysis has been performed under the assumption that $t^{+}$was so large that the policy never leads to full employment. Observe also that all the analysis of $\gamma$ (the education policy) can be transposed to the analysis of $\sigma$ (the wage subsidy policy). All the conclusion are the same since for any $\gamma=\sigma$, the two policies leads to the same level of welfare. This is of course also true for $\gamma^{*}=\sigma^{*}$.

So far, we have a general but not a precise idea of the consequences of the two policies. In order to highlight our analysis, let us interpret the numerical results of Table 1 . Indeed, in this table we give some numerical values of the different parameters and we study how $\gamma^{*}$ varies. We have selected four relevant cases. In the first two cases, (a) and (b), the $R E$ is positive and negative respectively (i.e., $\widetilde{t}^{N}$ is lower than $\widetilde{t}^{e}$ in (a) whereas it is greater in (b)). We have imposed the same values of the parameters except for $L$. In (a) $L$ has a lower value than in (b) which means that the unskilled sector is more productive in (b). The two other results (c) and (d) are limit cases.

Table 1: Numerical Simulation Results for the two non-selective policies

\begin{tabular}{|c|c|c|c|c|c|c|c|c|c|c|}
\hline \multicolumn{7}{|c|}{ Market Outcomes } & \multicolumn{4}{|c|}{ Policy Outcomes } \\
\hline & $\widetilde{t^{e}}$ & $\widetilde{t}^{N}$ & $t_{u}^{e}$ & $t_{u}^{N}$ & $W^{e}$ & $W^{N}$ & $\gamma^{*}=\sigma^{*}$ & $\bar{t}^{\gamma *}$ & $t_{u}^{\gamma *}$ & $W^{\gamma *}$ \\
\hline (a) & 1 & 0.8 & 2 & 1.7 & 4.5 & 4.39 & 0.155 & 0.94 & 2.01 & 4.5 \\
\hline (b) & 0.5 & 0.65 & 2.25 & 1.85 & 5.19 & 5.02 & 0.16 & 0.77 & 2.20 & 5.15 \\
\hline (c) & 0.5 & 0.51 & 1.02 & 1.02 & 2.55 & 2.55 & 0 & 0.51 & 1.02 & 2.55 \\
\hline$(\mathrm{d})$ & 1.5 & 0.75 & 1.52 & 1.14 & 11250 & 8438 & 0.5 & 1.5 & 2.27 & 11250 \\
\hline
\end{tabular}

(a) $H=5, L=4, E_{1}=3, E_{2}=2$

(b) $H=5, L=4.5, E_{1}=3, E_{2}=2$

(c) $H=5, L=4.9999, E_{1}=4.9, E_{2}=4.8998$

(d) $H=15000, L=0.0076, E_{1}=10000, E_{2}=0.005$ 
In the first one (case (c)), the values of the parameters are very similar and thus the two sectors are nearly identical. In this case, the competition is very fierce between the two firms and thus the wage outcome is very close to the Bertrand one. The equilibrium allocations are therefore very close to the competitive one (first best) and the government has no interest to set a positive $\gamma^{*}$. In the last case (case $\left.(\mathrm{d})\right)$, the two industries are very differentiated, both in terms of the productivities $(H>>L)$ and levels of qualification $\left(E_{1}>>\right.$ $\left.E_{2}\right)$. Firm 1 is clearly very dominant in the market and the competition is similar to a monopsonistic one. The government policy will therefore force the monopsonistic firm to implement the competitive allocations. Since the labor supply addressed to the monopsonistic firm is linear, this firm will hire half of the efficient labor force. The government will obviously set a $\gamma^{*}=0.5$ to restore the competitive allocations. Observe that these two polar cases ((c) and $(d))$ are respectively the less and the more inefficient ones and thus define the range of $\gamma^{*}$, i.e., $\gamma^{*} \in[0,0.5]$.

\section{Conclusion}

In this paper, we have proposed a stylized model of the labor market in which a high-skill sector interacts with a low-skill one. The upshot of the model is that workers' heterogeneity leads to interdependent equilibrium wages since each firm requires its workers to incur education costs (the high technology firm requiring more costly education). Thus, the lower the ability, the higher the education cost and the more difficult it is to find a job. In this framework, individuals with the lowest ability are the most likely to stay unemployed because their education cost is too high, even with respect to the low-skill sector. At the Nash equilibrium, two kinds of inefficiencies are observed: too few workers are employed and workers are missallocated across sectors.

Two types of policies are contemplated. The first one, the selective policies consist of subsidizing differently firms or workers by either subsidizing the education cost or the wage. We show that the first best allocation can be obtained by giving a larger subsidy to the high-technology firm than to the other one. For the non-selective policies, which consists of helping everybody by either subsidizing the education cost or the wage, the first best allocation can never be reached. Therefore, second best policies are implemented. Since the first best allocation involves both a reallocation effect between the two firms and an employment effect, the second best policies are restricted to a trade off between these two effects. In this context, we show that the two ad valorem subsidies are equivalent at the Nash equilibrium. 


\section{References}

[1] Bhaskar, V. and T. To (1999), "Minimum wage laws for Ronald McDonald monopsonies: A theory of monopsonistic competition", Economic Journal, 109, 190-203.

[2] Bulow, J. and L. Summers (1986), "A theory of dual labor markets with applications to industrial policy, and Keynesian unemployment", Journal of Labor Economics, 4, 376-414.

[3] Card, D. and A.B. Krueger (1995), Myth and Measurement. The Economics of the Minimum Wage, Princeton: Princeton University Press.

[4] Chang, C. and Y. Wang (1996), "Human capital investment under asymmetric information: The Pigovian conjecture revisited", Journal of Labor Economics, 14 , 505-519.

[5] Drèze, J. and E. Malinvaud (1994), "Growth and unemployment: the scope for a European initiative ", European Economy, 1, 75-106.

[6] Fiorillo, F., Santacroce, S. and S. Staffolani (2000), "Monopsonistic competition for the "best" workers", Labour Economics, 7, 313-334.

[7] Hamilton, J., Thisse, J-F. and Y. Zenou, (2000), "Wage competition with heterogeneous workers and firms", Journal of Labor Economics, 18, 453472 .

[8] Jellal, M., Thisse, J-F. and Y. Zenou (2001), "Demand uncertainty, mismatch, and (un)employment", Unpublished manuscript, University of Southampton.

[9] Juhn, C., Murphy, K. and B. Pierce (1993), "Wage inequality and the rise in return to skill", Journal of Political Economy, 101, 410-442.

[10] Katz, L., Loveman, G. and D. Blanchflower (1992), "A comparison of changes in the structure of wages in four OECD countries", NBER Working Paper 4297.

[11] Layard, R. (1994), "Unemployment: the way forward for Europe", Occasional paper 7, Centre for Economic Performance, London School of Economics.

[12] Layard, R. (1995), "What can active labor market policy do?", Discussion Paper 226, Centre for Economic Performance, London School of Economics. 
[13] Layard R., Nickell S. and Jackman (1991), Unemployment, Macroeconomic Performance and the Labour Market, Oxford: Oxford University Press.

[14] Marimon R. and F. Zilibotti (1999), "Unemployment versus mismatch of talents: Reconsidering unemployment benefits", Economic Journal, 109, 266-291.

[15] OECD (1996), Employment Outlook, Paris: OECD.

[16] Sattinger, M. (1993), "Assignment models of the distribution of earnings", Journal of Economic Literature, 31, 831-880.

[17] Stevens, M. (1994), "A theoretical model of on-the-job training with imperfect competition", Oxford Economic Papers, 46, 537-562.

[18] Thisse, J-F. and Y. Zenou (2000), "Skill mismatch and unemployment", Economics Letters, 69, 415-420.

[19] Wauthy, X. and Y. Zenou (2000), "How the adoption of a new technology is affected by the interaction between labour and product markets", in Market Structure and Competition Policy. Game-Theoretic Approaches, G. Norman and J-F. Thisse (eds.), ch. 12, 271-286, Cambridge: Cambridge University Press. 


\section{IZA Discussion Papers}

$\begin{array}{ll}\text { No. } & \text { Author(s) } \\ 260 & \begin{array}{l}\text { P. Cahuc } \\ \text { F. Postel-Vinay }\end{array} \\ 261 & \text { M. Lindahl }\end{array}$ Communism: Some Empirical Evidence 

A. Kaul
M. Kolmar

Efficiency Properties of Labor Taxation in a 

and the Rising Returns to Skill: US and France 1964-2000 

H. Bonin
G. Abío
E. Berenguer
J. Gil
C. Patxot 

A. Frederiksen
E. K. Graversen
N. Smith

Works Councils and Collective Bargaining in Wages Empirical Controversies in the Light of the Jones Model Industry: Evidence from a Comprehensive Enterprise Panel 

Quality
A. lbourk
B. Maillard
S. Perelman
H. R. Sneessens

The Matching Efficiency of Regional Labour Markets: A Stochastic Production Frontier

Estimation, France 1990-1995 